\title{
ANALISIS PENERIMAAN DAN PENGGUNAAN APLIKASI OVO DENGAN MENGGUNAKAN UNIFIED THEORY OF ACCEPTANCE AND USE OF TECHNOLOGY (UTAUT) DI KOTA DENPASAR
}

\author{
Gusi Putu Lestara Permana, Luh Putu Kristiari Dewi \\ Fakultas Ekonomi dan Bisnis, Universitas Pendidikan Nasional (Undiknas) Denpasar \\ lestarapermana@undiknas.ac.id
}

\begin{abstract}
Analysis of Acceptance and Use of OVO Applications Using Unified Theory of Acceptance and Use of Technology in Denpasar City

This study aims to determine the success of the acceptance and use of OVO applications by using the Unified Theory of Acceptance and Use of Technology (UTAUT) in Denpasar City. The UTAUT model in this study uses performance expectancy, effort expectancy, social influence, facilitating conditions, behavioral intention, use behavior, experience and voluntariness of use. The data acquisition in this study was processed using Partial Least Squares (PLS). The samples were 125 samples. Sources of data in this study are primary data sources sourced from questionnaire results that have been filled out by respondents. The research and testing instrument used is the outer model, while the data analysis technique used is the inner model and hypothesis testing.Based on the results, the hypothesis shows that performance expectations, effot expectations, social influences, facilitating conditions is positive towards behavior intentions. The behavioral intention is stated positively towards the use of behavior. However, the moderator variables that are declared not binding relations the independent variables and the dependent variable when receiving and using OVO applications in Denpasar.
\end{abstract}

Keywords: UTAUT Model, e-money, OVO application

\section{PENDAHULUAN}

Pada era globalisasi saat ini, teknologi telah berkembang dengan sangat pesat dan canggih. Perkembangan teknologi berdampak pada kehidupan sehari-hari, seperti melakukan pekerjaan dengan menggunakan teknologi dalam mempermudah pekerjaan seseorang, berkomunikasi dengan jarak dekat maupun jauh, dapat mengakses informasi dengan mudah dan dengan adanya teknologi berdampak pada tumbuh dan berkembangnya usaha atau bisnis baru. Saat ini penggunaan teknologi telah diimplementasikan pada bidang keuangan yaitu Financial Technology. Menurut Bank Indonesia (2019) Financial Technology merupakan sebuah hasil gabungan antara jasa keuangan dengan teknologi yang akhirnya mengubah model bisnis dari konvensional menjadi moderat, yang semula dalam proses transaksi harus bertatap muka tetapi kini dapat dilakukan dengan jarak jauh. Financial Technology hadir dan didukung dengan aktivitas masyarakat yang sehari-hari melakukan transaksi jual beli, peminjaman dana dan melakukan transfer dana. Hal tersebut memberikan dampak bagi masyarakat yaitu memberikan kemudahan dan keefektifan dalam menggunakan Financial Technology. 
Payment atau pembayaran merupakan salah satu aktivitas sehari-hari yang dilakukan oleh masyarakat. Dengan adanya payment atau pembayaran yang berbasis pada Financial Technology, dapat mendukung Gerakan Nasional Non Tunai (GNNT). GNNT merupakan program yang dicanangkan oleh Bank Indonesia bersama dengan Pemerintah yang bertujuan untuk mengurangi transaksi dengan menggunakan uang tunai, sehingga kedepannya masyarakat mulai memilih menggunakan instrumen non tunai dalam melakukan kegiatan yang berhubungan dengan keuangan seperti melakukan transaksi. Terdapat dua hal yang tercakup pada GNNT, yaitu Alat Pembayaran Menggunakan Kartu (APMK) dan E-money.

E-money merupakan pembayaran yang diterbtikan atas nilai uang yang telah disetorkan oleh konsumen, kemudian nilai uang tersebut akan tersimpan pada server atau chip, dan emoney akan disimpan dan dikelola oleh pengguna tetapi bukan sebagai simpanan sebagaimana yang diatur dalam Perundang-Undangan Perbankan (Bank Indonesia : 2019). Penggunaan emoney di lingkungan masyarakat telah memberikan manfaat seperti kemudahan dan keefektifan dalam bertransaksi, masyarakat tidak mendapatkan kembalian seperti barang (permen) dan dapat digunakan bertransaksi massal dengan bernilai kecil tetapi berfrekuensi tinggi seperti pembayaran toll, parkir, transportasi dan lain-lain. Salah satu e-money yang telah banyak digunakan di Indonesia adalah OVO.

OVO merupakan sebuah aplikasi e-money yang bergerak pada bidang layanan finansial dan bidang pembayaran. OVO dibentuk oleh PT. Visionet Internasional. Kehadiran OVO memberikan sebuah kemudahan dan kecepatan bertransaksi dengan didukung adanya fitur-fitur seperti pembayaran tagihan listrik, pulsa telepon, BPJS Kesehatan dan lain-lain. Selain itu OVO memberikan OVO points sebagai loyalty rewards bagi pengguna dalam melakukan transakasi pada OVO Cash di merchant-merchant rekanan OVO. Dengan adanya fitur-fitur tersebut yang mampu memenuhi kebutuhan masyarakat maka akan menarik perhatian masyarakat untuk menggunakan OVO.

Pada pengimplementasiannya, apabila seorang pengguna mengalami banyak kesulitan dalam menggunakan dan mengakses aplikasi OVO maka tidak menutup kemungkinan jika seseorang akan beralih menggunakan produk pesaing yang sesuai dengan harapan pengguna. Meskipun adanya aplikasi OVO saat ini, ternyata masih terdapat masyarakat yang cenderung untuk memilih dan melakukan transaksi secara tunai sehari-hari. Hal tersebut menimbulkan berbagai persepsi mengenai bagaimana pengimplementasian aplikasi OVO di masyarakat. Masyarakat sebagai penentu dan menilai bagaimana tingkat penerimaan dan penggunaan dalam menggunakan aplikasi OVO. Penilaian masyarakat tersebut dapat dijadikan sebuah evaluasi untuk OVO, agar kedepannya OVO dapat memperbaharui dan merancang lebih baik lagi agar memberikan kemudahan dan kenyamanan untuk masyarakat dalam bertransaksi menggunakan OVO, dan dengan kemudahan menggunakan e-money khususnya OVO maka akan mengubah pola transaksi masyarakat untuk bertransaksi non tunai.

Dilihat dari fenomena tersebut, untuk menilai dan mengukur tingkat penerimaan dan penggunaan aplikasi OVO yaitu dengan melakukan pengujian menggunakan model Unified Theory of Acceptance and Use of Technology (UTAUT). Model UTAUT pada penelitian ini menggunakan variabel independen yaitu performance expectancy, effort expectancy, social influence, facilitating conditions, behavioral intention dan variabel dependen yaitu use behavior. Penelitian ini juga menggunakan variabel moderasi yaitu experience dan voluntariness of use. 
Berdasarkan dari latar belakang penelitian ini, maka peneliti ingin melakukan penelitian ini dengan tujuan untuk menguji tingkat penerimaan dan penggunaan dengan menggunakan aplikasi OVO dengan judul penelitian "Analisis Penerimaan dan Penggunaan Aplikasi OVO Dengan Menggunakan Unified Theory of Acceptance and Use of Technology (UTAUT) di Kota Denpasar".

\section{KAJIAN LITERATUR}

\section{Unified Theory of Acceptance and Use of Technology (UTAUT)}

Unified Theory of Acceptance and Use of Technology (UTAUT) adalah sebuah pengembangan model gabungan baru terintegrasi yang telah dikembangkan oleh Venkatesh et al (2003) (Jogiyanto : 2008). Sebelumnya Venkatesh et al melakukan sebuah pengujian dengan delapan teori yang telah ada sebelumnya, hal tersebut dilakukan untuk membangun dan mengembangkan model UTAUT dan untuk menentukan variabel-variabel atau konstruk-konstruk yang signfikan untuk model UTAUT. Adapun variabel yang terangkum pada model UTAUT adalah sebagai berikut :

\section{Performance Expectancy}

Didefinisikan sebagai suatu variabel yang dapat mengukur tingkat kepercayaan seseorang menggunaka $n$ suatu sistem akan membantu pengguna untuk mendapatkan keuntungankeuntungan kinerja di pekerjaannya. Berdasarkan pada penelitian Winduwiratsoko (2018) terdapat empat indikator yaitu kegunaan persepian, kesesuaian pekerjaan, keuntungan relatif dan ekspektasi-ekspekstasi hasil.

2. Effort Expectancy

Didefinisikan sebagai tingkat kemudahan yang dihubungkan dengan penggunaan suatu sistem. Pada penelitian Winduwiratsoko (2018) terdapat tiga indikator pada effort expectancy yaitu kemudahan penggunaan persepsian, kerumitan dan kemudahan penggunaan.

3. Social Influence

Merupakan sejauh mana seorang individual mempersepsikan kepentingan yang dipercaya oleh orang lain yang akan mempengaruhinya menggunakan sistem yang baru. Indikator yang digunakan berdasarkan pada penelitian Winduwiratsoko (2018) adalah norma subyektif, faktor-faktor sosial dan image.

4. Facilitating Conditions

Didefinisikan sejauh mana seorang percaya bahwa infrastruktur organisasional dan teknikal tersedia untuk mendukung sistem. Pada facilitiating conditions menggunakan tiga indikator yaitu kontrol perilaku persepian, kondisi-kondisi pemfasilitasi dan kompabilitas (Winduwiratsoko : 2018)

\section{Behavioral Intention}

Merupakan salah satu hal yang mendasari pada hasrat, rencana, maksud atau keyakinan yang diorientasikan menuju sejumlah tujuan. Berdasarkan pada penelitian Aningsih (2015) dalam Putra (2019) adapun indikator yang digunakan adalah sering menggunakan, berencana menggunakan dan memprediksi untuk menggunakan.

6. Use Behavior 
Didenisikan sebagai suatu kondisi nyata pada penggunaan suatu teknologi informasi. Berdasarkan pada penelitian Aningsih (2018) dalam Putra (2019) terdapat indikator yaitu kepuasan terhadap sistem, kepuasan terhadap penggunaan dan kepuasan dalam pengalaman.

\section{Gender}

Berdasarkan pada penelitian Minton dan Schneider (1980) dalam Jogiyanto (2008) menjelaskan perbedaan gender menunjukkan pria cenderung lebih tinggi di orientasi tugas, sehingga performance expectancy yang berfokus pada penyelesaian tugas cenderung pada pria.

\section{Age}

Pada penelitian di sikap yang berhubungan dengan pekerjaan, menyatakan bahwa pekerjapekerja lebih muda akan lebih penting untuk kompensasi-kompensasi ektrinsik (Porter : 1963 dalam Jogiyanto : 2008).

\section{Experience}

Merupakan pelatihan perkenalan pada sistem dengan kemampuan yang dibutuhkan. Adapaun indikator pada experience menurut Bhilawa (2010) adalah sudah pernah menggunakan aplikasi OVO, banyaknya pengalaman menggunakan aplikasi OVO, berapa lama menggunakan aplikasi OVO.

\section{Voluntariness of use}

Didefinisikan sebagai seseorang menggunakan sebuah sistem dengan sendirinya, tanpa adanya paksaan dari orang lain. Berdasarkan pada penelitian Bistolen (2018) terdapat tiga indikator yaitu menggunakan aplikasi OVO selagi berkaitan dengan pekerjaan atau sekolah, aplikasi OVO tidak disyaratkan dalam penggunaannya, dan aplikasi OVO meningkatkan efektivitas, tapi tidak diwajibkan.

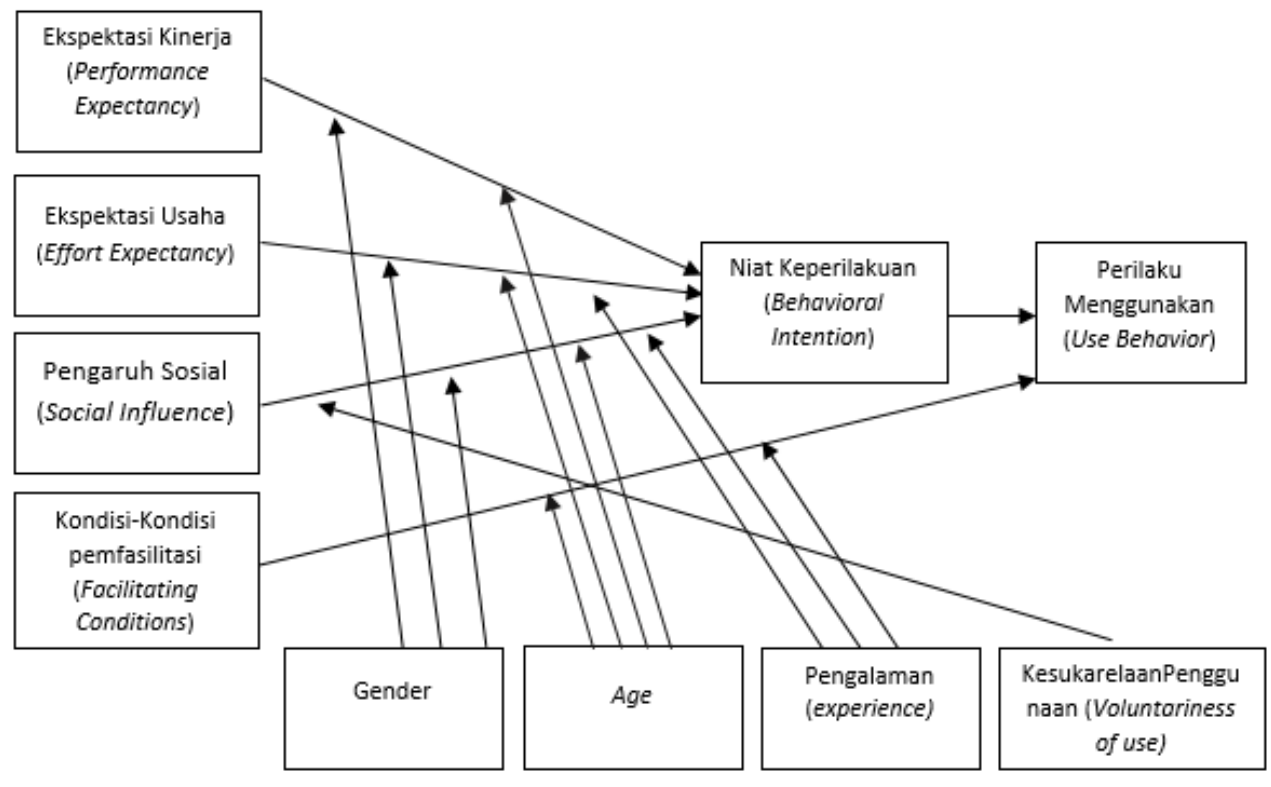

Gambar 1 : Model UTAUT 


\section{E-Money}

E-money merupakan suatu alat pembayaran non tunai yang memiliki unsur yaitu diterbitkan atas nilai uang yang telah disetorkan oleh konsumen, kemudian uang tersebut akan tersimpan secara elektronik pada server atau chip dan e-money dapat dikelola dengan bijak oleh konsumen tetapi e-money tidak termasuk simpanan sebagaimana yang tercantum pada PerundangUndangan yang mengatur tentang perbankan (Bank Indonesia : 2019). Kehadiran e-money memberikan manfaat bagi masyarakat, yaitu masyarakat dalam bertransaksi tidak mendapatkan uang kembalian berupa uang kecil (receh) atau berupa barang seperti permen, penggunaan $e$ money dapat mengurangi adaya peredaran uang palsu di masyarakat dan penggunaan e-money sangat praktis digunakan pada transaksi massal yang berfrekuensi tinggi seperti pembayaran toll, parkir, transportasi dan lain-lain. Namun, selain manfaat positif yang diberikan kepada masyarakat, e-money memiliki resiko yang harus diperhatikan oleh penggunanya. Resiko tersebut adalah e-money dapat hilang dan digunakan oleh pihak lain yang tidak dapat diklaim oleh kepada penerbit dan pengguna harus lebih memperhatikan pada penggunaan e-money karena jika e-money ditempelkan sebanyak dua kali pada mesin reader akan mengurangi saldo dari e-money tersebut.

\section{OVO}

OVO merupakan aplikasi smart yang memberikan masyarakat layanan pembayaran dan transaksi secara online (OVO : 2019). OVO didirikan oleh PT. Visionet Internasional dan telah resmi terdaftar oleh Bank Indonesia pada No. 19/661/DKSP/Srt/B pada 7 Agustus 2017. OVO saat ini bekerjasama dengan Grab dan merchant-merchant yang tersebar di Indonesia yaitu pada pusat perbelanjaan, toko, café dan restoran. OVO memberikan kemudahan dan kenyamanan bertransakasi bagi penggunanya, seperti adanya fitur pembayaran tagihan listrik, pulsa telepon, paket data, pascabayar, BPJS Kesehatan, asuransi dan lain-lain. Daya tarik masyarakat untuk menggunakan OVO adalah adanya OVO Cash dan OVO Points. OVO Cash yaitu dapat digunakan di merchant-merchant rekanan OVO, isi ulang (top up) dan pengecekan saldo. Sedangkan OVO Points adalah loyalty rewards dimana pengguna mendapatkan point saat melakukan transaksi di merchant OVO dan kemudian point tersebut dapat ditukarkan pada penawaran menarik pada merchant rekanan OVO. 


\section{Kerangka Pemikiran}

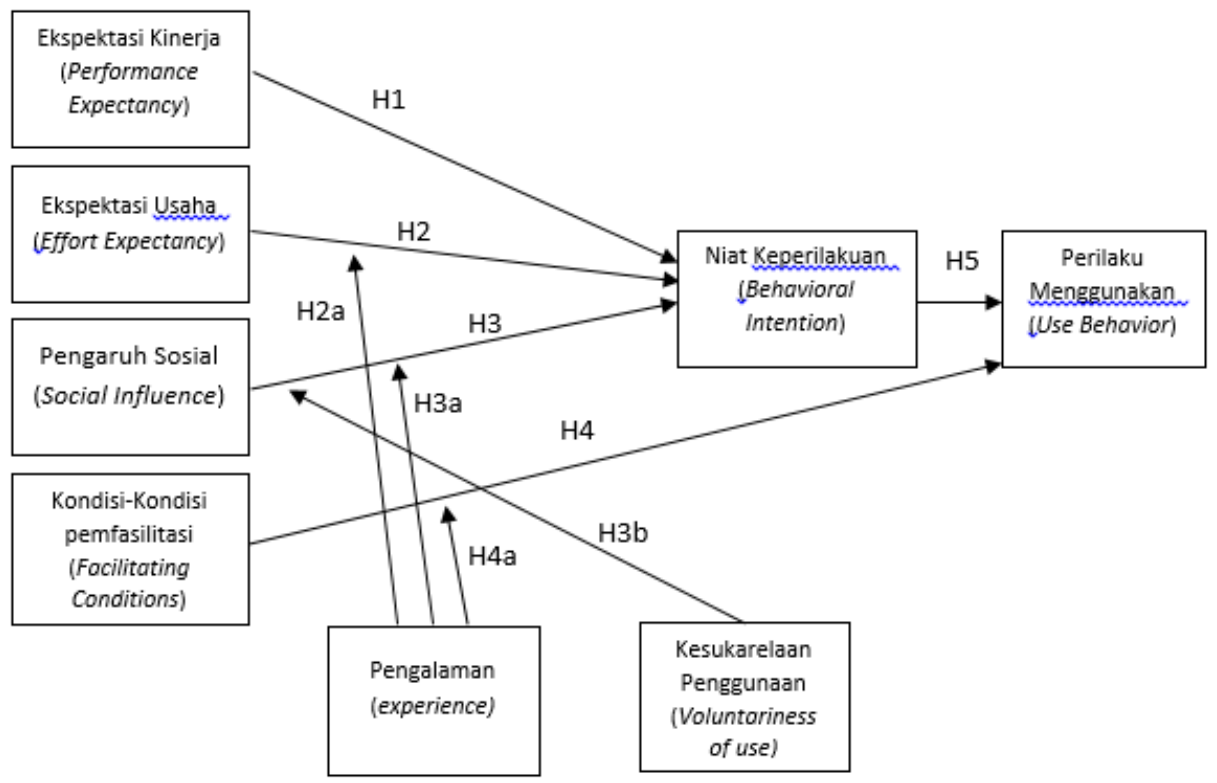

Gambar 2 : Kerangka Pemikiran

\section{Hipotesis Penelitian}

$\mathrm{H} 1$ : Performance expectancy berpengaruh positif terhadap behavioral intention.

$\mathrm{H} 2$ : Effort expectancy berpengaruh positif terhadap behavioral intention.

$\mathrm{H} 2 \mathrm{a}$ : Experience memperkuat hubungan effort expectancy dengan behavioral intention.

H3 : Social influence berpengaruh positif terhadap behavioral intention.

$\mathrm{H} 3 \mathrm{a}$ : Experience memperkuat hubungan social influence dengan behavioral intention.

$\mathrm{H} 3 \mathrm{~b}$ : Voluntariness of use memperkuat hubungan social influence dengan behavioral intention.

H4 : Facilitating conditions berpengaruh positif terhadap use behavior.

$\mathrm{H} 4 \mathrm{a}$ : Experience memperkuat hubungan facilitating conditons dengan use behavior.

H5 : Behavioral intention berpengaurh positif terhadap use behavior.

\section{METODE}

Lokasi dilakukannya penelitian ini adalah di Kota Denpasar. Populasi dalam penelitian ini yaitu masyarakat Kota Denpasar yang menggunakan aplikasi OVO. Penelitian ini menggunakan teknik purposive sampling, dan jumlah sampel yaitu 125 sampel. Dalam penelitian ini menggunakan jenis data kuantitatif dan sumber data yang digunakan adalah sumber data primer. Data primer tersebut diperoleh langsung dari pengisian kuesioner oleh pengguna OVO. Teknik pengumpulan data menggunakan teknik kuesioner dengan skala likert. Teknik pendistribusian kuesioner menggunakan metode self-administered yaitu diberikan langsung kepada responden 
dan memberikan pengarahan serta informasi mengenai pengisian kuesioner. Dalam melakukan pengolahan data primer yang telah diperoleh yaitu diolah menggunakan Partial Least Squares (PLS). Pada pengujian instrumen penelitian dan pengujiannya menggunakan metode outer model, sedangkan teknik analisis dalam penelitian ini menggunakan metode inner model dan pengujian hipotesis.

\section{HASIL DAN PEMBAHASAN}

\section{Karakteristik Responden}

Hasil dari penyebaran kuesioner yang diperoleh dari 125 responden, menunjukkan bahwa jenis kelamin yang mendominasi adalah perempuan dengan jumlah responden perempuan sebanyak 76 dengan persentase $60,8 \%$, sedangkan responden laki-laki berjumlah 49 responden dengan persentase $39,2 \%$. Karakteristik responden berdasarkan usia didominasi oleh usia 17-25 tahun berjumlah 77 responden dengan persentase $61,6 \%$, sisanya rentang usia $26-35$ tahun sebanyak 27 responden dengan persentase $21,6 \%$ dan $>35$ tahun yaitu jumlah responden 21 dengan persentase $16,8 \%$. Pada karakteristik responden berdasarkan domisili didominasi oleh Denpasar Selatan yaitu berjumlah 35 responden dengan persentase $28 \%$ dan domisili dengan jumlah responden terendah adalah Denpasar Barat yang berjumlah 27 responden dengan persentase responden yaitu $21,6 \%$.

\section{Pengujian Model Pengukuran (Outer Model)}

Pengujian model pengukuran menggambarkan sebuah hubungan antara blok indikator dengan variabel latennya. Berikut merupakan gambar hasil dari pengujian model pengukuran (outer model).

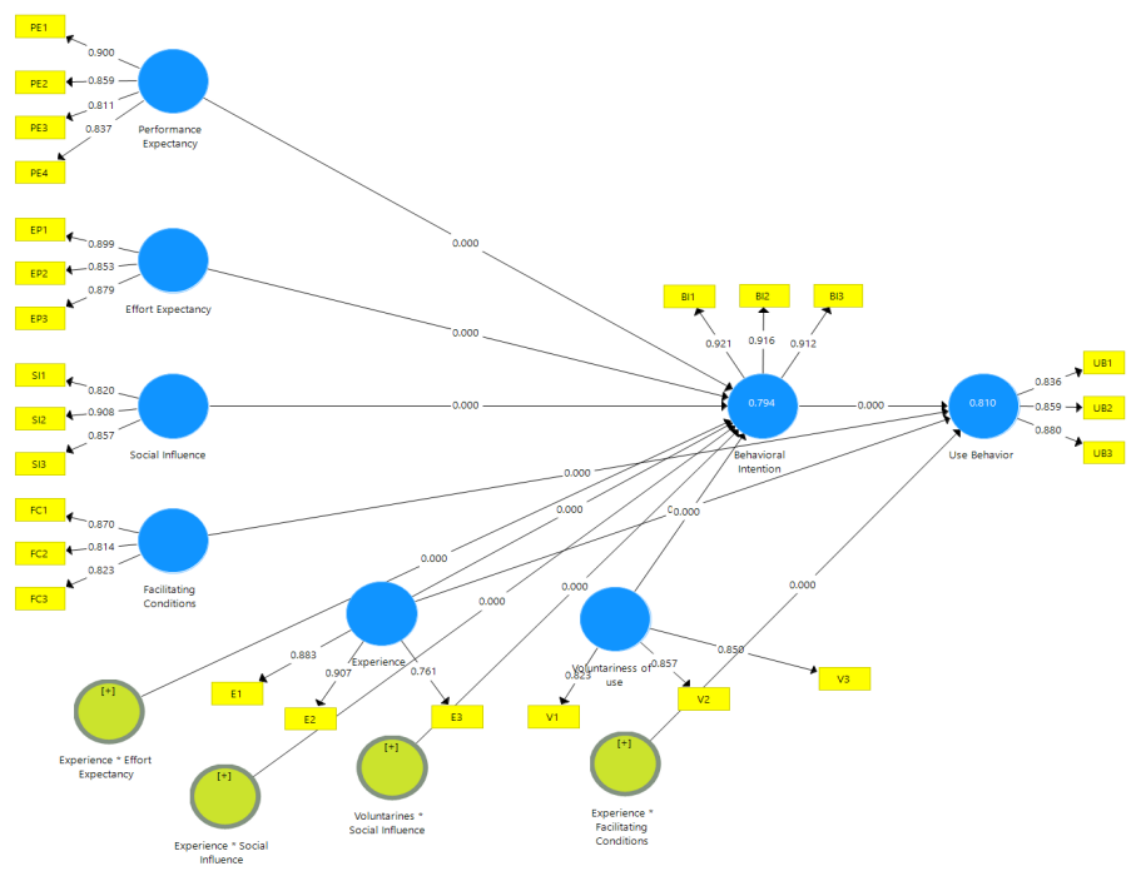

Gambar 3 : Hasil Pengujian Model Pengukuran (Outer Model) 
Validitas Konvergen

\begin{tabular}{|c|c|c|c|c|c|c|c|c|c|c|c|c|}
\hline & $\mathrm{BI}$ & EE & $E$ & $E$ * EE & $E{ }^{*} F C$ & $E * S I$ & FC & PE & SI & UB & $V * S I$ & v \\
\hline Bl1 & 0.921 & & & & & & & & & & & \\
\hline $\mathrm{BI} 2$ & 0.916 & & & & & & & & & & & \\
\hline $\mathrm{BI3}$ & 0.912 & & & & & & & & & & & \\
\hline E1 & & & 0.883 & & & & & & & & & \\
\hline E2 & & & 0.907 & & & & & & & & & \\
\hline E3 & & & 0.761 & & & & & & & & & \\
\hline EP1 & & 0.899 & & & & & & & & & & \\
\hline EP2 & & 0.853 & & & & & & & & & & \\
\hline EP3 & & 0.879 & & & & & & & & & & \\
\hline $\begin{array}{c}\mathrm{EE}^{*} \\
\mathrm{EE}\end{array}$ & & & & 1.349 & & & & & & & & \\
\hline FC1 & & & & & & & 0.870 & & & & & \\
\hline FC2 & & & & & & & 0.814 & & & & & \\
\hline FC3 & & & & & & & 0.823 & & & & & \\
\hline $\begin{array}{c}\text { FC }^{*} \\
\mathbf{E}^{2}\end{array}$ & & & & & 1.523 & & & & & & & \\
\hline PE1 & & & & & & & & 0.900 & & & & \\
\hline PE2 & & & & & & & & 0.859 & & & & \\
\hline PE3 & & & & & & & & 0.811 & & & & \\
\hline PE4 & & & & & & & & 0.837 & & & & \\
\hline SI1 & & & & & & & & & 0.820 & & & \\
\hline SI2 & & & & & & & & & 0.908 & & & \\
\hline SI3 & & & & & & & & & 0.857 & & & \\
\hline $\begin{array}{c}\mathrm{SI}^{*} \\
\mathrm{E}\end{array}$ & & & & & & 1.218 & & & & & & \\
\hline $\mathrm{SI}^{*}$ & & & & & & & & & & & 1.130 & \\
\hline UB1 & & & & & & & & & & 0.836 & & \\
\hline UB2 & & & & & & & & & & 0.859 & & \\
\hline UB3 & & & & & & & & & & 0.880 & & \\
\hline V1 & & & & & & & & & & & & 0.823 \\
\hline V2 & & & & & & & & & & & & 0.857 \\
\hline V3 & & & & & & & & & & & & 0.850 \\
\hline
\end{tabular}

Tabel 1 : Hasil Uji Outer Loading 
Berdasarkan pada hasil nilai perolehan dari hasil uji outer loading, menunjukkan bahwa seluruh indikator pada variabel tersebut dinyatakan layak digunakan sebagai alat ukur dalam pengujian model pengukuran (outer model). Hal tersebut dapat dikatakan layak dalam alat ukur model pengukuran (outer model) karena seluruh nilai dari masing-masing variabel yaitu lebih dari 0,7 . Dengan demikian dapat dinyatakan valid.

\section{Validitas Diskriminan}

\begin{tabular}{|c|c|c|c|c|c|c|c|c|c|c|c|c|}
\hline & BI & EE & $E$ & $E$ * $E E$ & $E *{ }^{*} \mathrm{FC}$ & $E * S I$ & FC & PE & SI & UB & $V * S I$ & v \\
\hline BI & 0.917 & & & & & & & & & & & \\
\hline EE & 0.771 & 0.877 & & & & & & & & & & \\
\hline$E$ & 0.839 & 0.799 & 0.853 & & & & & & & & & \\
\hline$E$ * $E E$ & -0.300 & -0.132 & -0.324 & 1.000 & & & & & & & & \\
\hline$E *{ }^{*} F C$ & -0.335 & -0.224 & -0.395 & 0.782 & 1.000 & & & & & & & \\
\hline$E^{*} \mathrm{SI}$ & -0.191 & -0.110 & -0.258 & 0.859 & 0.817 & 1.000 & & & & & & \\
\hline FC & 0.672 & 0.634 & 0.650 & -0.252 & -0.341 & -0.238 & 0.836 & & & & & \\
\hline PE & 0.746 & 0.619 & 0.715 & -0.358 & -0.395 & -0.249 & 0.569 & 0.852 & & & & \\
\hline SI & 0.767 & 0.752 & 0.719 & -0.099 & -0.190 & 0.045 & 0.594 & 0.675 & 0.862 & & & \\
\hline UB & 0.884 & 0.771 & 0.812 & -0.287 & -0.368 & -0.191 & 0.688 & 0.766 & 0.796 & 0.858 & & \\
\hline$V * S I$ & -0.024 & 0.017 & -0.079 & 0.687 & 0.685 & 0.827 & -0.127 & -0.110 & 0.180 & -0.025 & 1.000 & \\
\hline v & 0.765 & 0.756 & 0.753 & -0.192 & -0.247 & -0.073 & 0.578 & 0.683 & 0.724 & 0.782 & 0.029 & 0.843 \\
\hline
\end{tabular}

Tabel 2 : Hasil Uji Validitas Diskriminan Korelasi Variabel Laten

Berdasarkan pada hasil uji validitas diskriminan korelasi variabel laten menunjukkan bahwa masing-masing variabel lebih besar dari 0,7. Hal tersebut dapat dilihat secara diagonal, yang menunjukkan bahwa nilai pada masing-masing variabel bernilai lebih besar 0,7 dibandingkan hubungan variabel dengan variabel lainnya. Hasil tersebut dinyatakan valid.

Terdapat uji lainnya untuk mengukur validitas diskriminan adalah dengan cara membandingkan akar Average Variance Extracted (AVE). Adapun nilai AVE yang dibutuhkan pada uji validitas diskriminan ini adalah AVE $>0,5$. Berikut adalah hasil dari validitas diskriminan yang memiliki nilai $A V E>0,5$ dan dinyatakan valid.

\begin{tabular}{|l|c|}
\hline & $\begin{array}{c}\text { Average Variance } \\
\text { Extracted (AVE) }\end{array}$ \\
\hline Behavioral Intention & 0.840 \\
\hline Effort Expectancy & 0.769 \\
\hline Experience & 0.727 \\
\hline Experience * Effort Expectancy & 1.000 \\
\hline Experience * Facilitating Conditions & 1.000 \\
\hline Experience * Social Influence & 1.000 \\
\hline
\end{tabular}




\begin{tabular}{|l|l|} 
Facilitating Conditions & 0.699 \\
\hline Performance Expectancy & 0.727 \\
\hline Social Influence & 0.744 \\
\hline Use Behavior & 0.737 \\
\hline Voluntarines * Social Influence & 1.000 \\
\hline Voluntariness of use & 0.711 \\
\hline
\end{tabular}

Tabel 3 : Hasil Uji Validitas AVE

\section{Uji Reliabilitas}

\begin{tabular}{|l|c|c|}
\hline & $\begin{array}{l}\text { Cronbach's } \\
\text { Alpha }\end{array}$ & $\begin{array}{l}\text { Composite } \\
\text { Reliability }\end{array}$ \\
\hline Behavioral Intention & 0.905 & 0.940 \\
\hline Effort Expectancy & 0.850 & 0.909 \\
\hline Experience & 0.811 & 0.888 \\
\hline Experience * Effort Expectancy & 1.000 & 1.000 \\
\hline Experience * Facilitating Conditions & 1.000 & 1.000 \\
\hline Experience * Social Influence & 1.000 & 1.000 \\
\hline Facilitating Conditions & 0.784 & 0.874 \\
\hline Performance Expectancy & 0.874 & 0.914 \\
\hline Social Influence & 0.827 & 0.897 \\
\hline Use Behavior & 0.821 & 0.894 \\
\hline Voluntarines * Social Influence & 1.000 & 1.000 \\
\hline Voluntariness of use & 0.797 & 0.881 \\
\hline
\end{tabular}

Tabel 4 : Hasil Uji Reliabilitas

Berdasarkan pada hasil uji reliabilitas, bahwa nilai Cronbach's Alpha dan Composite Reliability pada setiap variabelnya memiliki nilai lebih dari 0,7. Maka dari itu dapat disimpulkan bahwa pada uji reliabilitas dapat dinyatakan valid dan memenuhi syarat.

\section{Pengujian Model Struktural (Inner Model)}




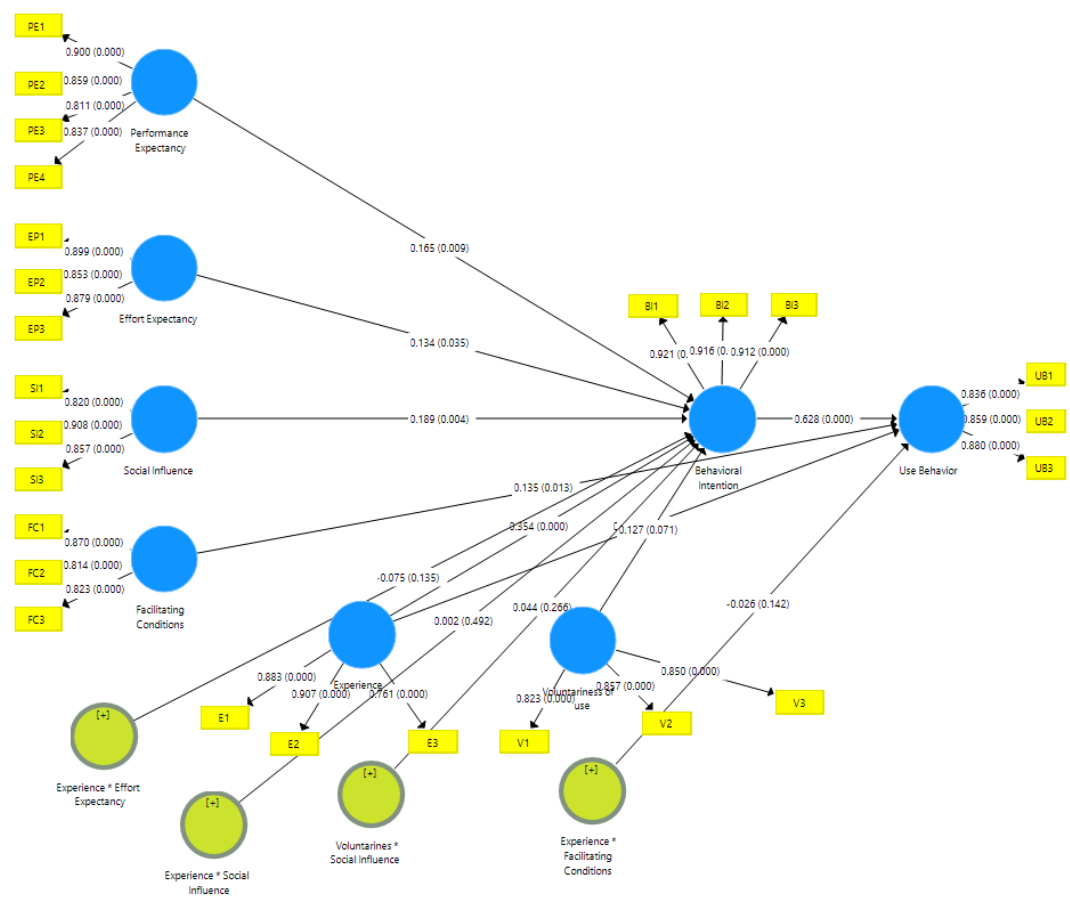

Gambar 4 : Hasil Pengujian Model Struktural (Inner Model)

Pada gambar diatas menunjukkan sebuah hasil pengujian model struktrual (Inner Model) yaitu menjelaskan mengenai hubungan kausalitas antar variabel intern yang dibangun berdasarkan pada substansi teori. Pengujian model struktural (Inner Model) akan melakukan pengujian sebagai berikut :

\section{R-Square $\left(\mathbf{R}^{2}\right)$}

\begin{tabular}{|l|r|r|}
\hline & R Square & R Square Adjusted \\
\hline Behavioral Intention & 0.794 & 0.780 \\
\hline Use Behavior & 0.810 & 0.804 \\
\hline
\end{tabular}

Tabel 5 : Hasil Uji R-Square $\left(\mathrm{R}^{2}\right)$

Pada hasil Uji $\mathrm{R}$-Square $\left(\mathrm{R}^{2}\right)$ dijelaskan bahwa nilai $\mathrm{R}^{2}$ untuk variabel performance expectancy, effort expectancy, social influence dan facilitating conditions terhadap behavioral intention sebesar 0,794 termasuk baik yang menunjukkan memiliki besar pengaruh 0,794 x 100\% $=79,4 \%$, sedangkan sisanya sebesar $20,6 \%$ dijelaskan oleh variasi di luar model penelitian yang digunakan.

Pada nilai $\mathrm{R}^{2}$ variabel performance expectancy, effort expectancy, social influence dan facilitating conditions terhadap use behavior sebesar 0,804 termasuk moderat yang menunjukkan memiliki besar pengaruh $0,810 \times 100 \%=81 \%$, sedangkan sisanya sebesar $19 \%$ dijelaskan oleh variasi di luar model penelitian yang digunakan. 


\section{Pengujian Hipotesis}

\begin{tabular}{|l|r|r|r|r|r|}
\hline & \multicolumn{1}{|l|}{$\begin{array}{l}\text { Original } \\
\text { Sample } \\
\text { (O) }\end{array}$} & $\begin{array}{l}\text { Sample } \\
\text { Mean } \\
\text { (M) }\end{array}$ & $\begin{array}{l}\text { Standard } \\
\text { Deviation } \\
\text { (STDEV) }\end{array}$ & $\begin{array}{l}\text { T Statistics } \\
(|\mathrm{O} / \mathrm{STDEV}|)\end{array}$ & P Values \\
\hline $\begin{array}{l}\text { Performance Expectancy -> } \\
\text { Behavioral Intention }\end{array}$ & 0.165 & 0.163 & 0.073 & 2.251 & 0.012 \\
\hline $\begin{array}{l}\text { Effort Expectancy -> Behavioral } \\
\text { Intention }\end{array}$ & 0.134 & 0.135 & 0.076 & 1.769 & 0.039 \\
\hline $\begin{array}{l}\text { Experience * Effort Expectancy -> } \\
\text { Behavioral Intention }\end{array}$ & -0.075 & -0.076 & 0.071 & 0.146 \\
\hline $\begin{array}{l}\text { Social Influence -> Behavioral } \\
\text { Intention }\end{array}$ & 0.189 & 0.186 & 0.070 & 2.687 & 0.004 \\
\hline $\begin{array}{l}\text { Experience * Social Influence -> } \\
\text { Behavioral Intention }\end{array}$ & 0.002 & 0.010 & 0.092 & 0.018 & 0.493 \\
\hline $\begin{array}{l}\text { Voluntarines * Social Influence -> } \\
\text { Behavioral Intention }\end{array}$ & 0.044 & 0.035 & 0.076 & 0.584 & 0.280 \\
\hline $\begin{array}{l}\text { Facilitating Conditions -> Use } \\
\text { Behavior }\end{array}$ & 0.135 & 0.132 & 0.057 & 2.358 & 0.009 \\
\hline $\begin{array}{l}\text { Experience * Facilitating } \\
\text { Conditions -> Use Behavior }\end{array}$ & -0.026 & -0.023 & 0.024 & 1.077 & 0.141 \\
\hline $\begin{array}{l}\text { Behavioral Intention -> Use } \\
\text { Behavior }\end{array}$ & 0.628 & 0.628 & 0.077 & 8.100 & 0.000 \\
\hline
\end{tabular}

Tabel 5 : Hasil Uji Bootstrapping (T-Test)

Berdasarkan pada tabel 5, diperoleh nilai original sample $(\mathrm{O})$ dan t-statistic untuk masingmasing variabel yang dijelaskan pada tabel berikut :

\begin{tabular}{|c|c|c|c|c|}
\hline Hipotesis & Efek & Original Sample (0) & T-statistic & Keterangan \\
\hline $\mathrm{H} 1$ & $\mathrm{PE}->\mathrm{BI}$ & 0,165 & 2,251 & Diterima \\
\hline $\mathrm{H} 2$ & $\mathrm{EP}->\mathrm{BI}$ & 0,134 & 1,769 & Diterima \\
\hline $\mathrm{H} 2 \mathrm{a}$ & $\mathrm{E}^{\star} \mathrm{EP}->\mathrm{BI}$ & $-0,075$ & 1,057 & Ditolak \\
\hline $\mathrm{H} 3$ & $\mathrm{SI}->\mathrm{BI}$ & 0,189 & 2,687 & Diterima \\
\hline $\mathrm{H} 3 \mathrm{a}$ & $\mathrm{E}^{\star} \mathrm{SI}->\mathrm{BI}$ & 0,002 & 0,018 & Ditolak \\
\hline $\mathrm{H} 3 \mathrm{~b}$ & $\mathrm{~V}^{\star} \mathrm{SI}->\mathrm{BI}$ & 0,044 & 0,584 & Diterima \\
\hline $\mathrm{H} 4$ & $\mathrm{FC}->\mathrm{UB}$ & 0,135 & 2,358 & Diterima \\
\hline $\mathrm{H} 4$ & $\mathrm{E}^{\star} \mathrm{FC}->\mathrm{UB}$ & $-0,026$ & 1,077 & Ditolak \\
\hline $\mathrm{H} 5$ & $\mathrm{BI}->\mathrm{UB}$ & 0,628 & 8,100 & Diterima \\
\hline
\end{tabular}

Tabel 6 : Hasil Hipotesis

\section{Pembahasan Hasil Penelitian}

\section{Pengaruh Performance Expectancy Terhadap Behavioral Intention}

Berdasarkan pada analisis data bahwa performance expectancy berpengaruh positif terhadap behavioral intention. Nilai t-statistic yang diperoleh sebesar 2,251 lebih besar dari t-tabel yaitu 1,64. Nilai original sample $(0)$ yang diperoleh sebesar 0,165 menunjukkan hubungan yang positif antara performance expectancy dengan behavioral intention. Apabila performance expectancy semakin meningkat maka behavioral intention akan meningkat pula dengan penerimaan dan penggunaan aplikasi OVO di Kota Denpasar. 
Dalam penelitian ini, pengguna aplikasi OVO merasa diberikan keuntungan dalam menggunakan aplikasi OVO, seperti aplikasi OVO dirasa efektif digunakan oleh pengguna dalam memudahkan bertransaksi non tunai. Hasil penelitian tersebut didukung dengan hasil penelitian Pertiwi dan Dodik (2017) yang menyatakan bahwa performance expectancy berpengaruh positif terhadap minat penggunan yang diadopsi terhadap behavioral intention dilakukan pada objek penelitian pada mobile banking.

\section{Pengaruh Effort Expectancy Terhadap Behavioral Intention}

Pada hasil analisis data bahwa diperoleh nilai t-statistics sebesar 1,769 lebih besar dari nilai t-tabel yaitu 1,64. Hasil penelitian ini memperoleh nilai original sample (O) yang menunjukkan arah positif antara effort expectancy terhadap behavioral intention dengan nilai positif 0,134 . Hal ini membuktikan adanya hubungan positif pada variabel effort expectancy dengan behavioral intention. Berdasarkan pada hasil analisis tersebut disimpulkan bahwa effort expectancy berpengaruh positif terhadap behavioral intention, hal ini berarti jika effort expectancy semakin meningkat maka behavioral intention semakin meningkat pula pada penerimaan dan penggunaan aplikasi OVO di Kota Denpasar.

Pada hasil penelitian ini bahwa pengguna aplikasi OVO merasakan kemudahan dalam menggunakan aplikasi OVO, sehingga masyarakat merasa lebih efisien dalam segi tenaga dan waktu untuk proses transaksi. Hasil penelitian tersebut didukung dengan hasil penelitian oleh Rahmantanto dan Ramantoko (2019) yang menyebutkan bahwa effort expectancy berpengaruh positif terhadap behavioral intention pada minat nasabah PT Bank Rakyat Indonesia menggunakan Layanan BRI Mobile.

\section{Pengaruh Experience Terhadap Effort Expectancy Dengan Behavioral Intention}

Sesuai pada hasil analisis data yang telah dilakukan bahwa diperoleh nilai t-statistic sebesar 1,057 lebih kecil dari nilai t-tabel yaitu 1,64. Pada original sample (O) diperoleh nilai sebesar 0,075, sehingga menunjukkan adanya hubungan negatif pada experience terhadap effort expectancy dengan behavioral intention. Berdasarkan hasil tersebut maka dapat disimpulkan bahwa experience tidak dapat memperkuat hubungan effort expectancy dengan behavioral intention. Hal ini berarti apabila experience tidak mempengaruhi peningkatan maupun penurunan hubungan effort expectancy dengan behavioral intention pada penerimaan dan penggunaan aplikasi OVO di Kota Denpasar.

Hasil penelitian menyatakan bahwa experience dengan indikator pernah menggunakan aplikasi OVO, banyaknya pengalaman menggunakan aplikasi OVO dan lama menggunakan aplikasi OVO tidak dapat memperkuat hubungan effort expectancy dengan behavioral intention.Dari hasil penelitian ini, didukung dengan hasil penelitian Rianadewi (2019). Dalam penelitiannya diperoleh hasil bahwa experience tidak mempunyai efek moderasi yang memperkuat hubungan effort expectancy dengan behavioral intention pada objek penelitian penggunaan E-Learning Share-ITS.

\section{Pengaruh Social Influence Terhadap Behavioral Intention}

Berdasarkan pada hasil analisis data bahwa nilai t-statistic variabel social influence yaitu sebesar 2,687 lebih besar dari nilai t-tabel yaitu 1,64. Pada original sample (O) diperoleh nilai 
positif 0,189 . Hasil tersebut menunjukkan adanya hubungan positif antara social influence terhadap behavioral intention. Dari hasil penelitian tersebut menunjukkan bahwa social influence berpengaruh positif terhadap behavioral intention, hal ini berarti jika social influence semakin meningkat maka behavioral intention semakin meningkat pula dengan penerimaan dan penggunaan aplikasi OVO di Kota Denpasar.

Berdasarkan pada hasil penelitian, dapat dijelaskan bahwa dalam lingkungan sekitar pengguna OVO dapat memberikan kepercayaan atau informasi yang baik bagi seseorang yang akan menggunakan aplikasi OVO, maka akan mempengaruhi pada niat keperilakuan. Dari hasil penelitian tersebut didukung dengan penelitian sebelumnya yaitu hasil penelitian oleh Rahmatillah, et al (2018), dimana hasil penelitiannya menyebutkan social influence berpengaruh positif dan signifikan terhadap behavioral intention pada perilaku penggunaan Financial Technology.

\section{Pengaruh Experience Terhadap Social Influence Dengan Behavioral Intention}

Berdasarkan pada analisis data, diperoleh hasil t-statistics sebesar 0,018 lebih kecil dari nilai t-tabel yaitu 1,64. Pada original sample (O) menunjukkan hasil dengan nilai positif 0,002 sehingga menunjukkan adanya hubungan positif pada variabel experience terhadap social influence dengan behavioral intention. Meski nilai t-statistic lebih kecil dari t-tabel, dapat disimpulkan bahwa experience tidak memperkuat hubungan social influence dengan behavioral intention. Hal ini berarti experience tidak mempengaruhi peningkatan maupun penurunan antara hubungan social influence dengan behavioral intention pada penerimaan dan penggunaan aplikasi OVO di Kota Denpasar.

Dilihat pada hasil penelitian tersebut, untuk menunjukkan experience memperkuat hubungan social influence dengan behavioral intention digunakan indikator-indikator lainnya yang mendukung pengaruh tersebut, seperti indikator yang menunjukkan pengalaman yang baik untuk dapat mempengaruhi lingkungan sekitar dalam menggunakan aplikasi OVO. Hasil penelitian dari Yunis et al (2017) mendukung hasil pada penelitian ini. Dalam penelitian Mentaya et al (2017) disebutkan bahwa experience tidak experience tidak memoderasi hubungan social influence dengan behavioral intention pada penerimaan aplikasi Brilian.

\section{Pengaruh Voluntariness of Use Terhadap Social Influence Dengan Behavioral Intention}

Pada variabel voluntariness of use diperoleh nilai t-statistic sebesar 0,584 lebih kecil dari nilai t-tabel yaitu 1,64. Pada original sample $(\mathrm{O})$ yaitu diperoleh nilai 0,044 . Hasil original sample (O) menyatakan adanya hubungan yang positif pada voluntariness of use terhadap social influence dengan behavioral intention. Berdasarkan pada hasil penelitian tersebut, dapat disimpulkan bahwa voluntariness of use tidak memperkuat hubungan social influence dengan behavioral intention. Dengan demikian voluntariness of use tidak mempengaruhi peningkatan maupun penurunan antara hubungan social influence dengan behavioral intention pada penerimaan dan penggunaan aplikasi OVO di Kota Denpasar.

Berdasarkan pada hasil penelitian ini bahwa penggunaan aplikasi OVO tidak bersifat wajib, maka perlu didukung oleh lingkungan sekitarnya. Jika pada lingkungan sekitarnya sangat sedikit pengguna OVO atau penggunaan yang tidak konsisten menggunakan aplikasi OVO secara terus 
menerus serta tidak memberikan kesan yang baik dalam menggunakan aplikasi OVO, maka seseorang akan memiliki minat sedikit dalam menggunakan OVO bahkan pemakaian OVO yang tidak konsisten. Hasil penelitian ini didukung dengan hasil penelitian yang oleh Mentaya et al (2015). Dalam penelitiannya disebutkan bahwa voluntariness of use tidak memoderasi hubungan social influence dengan behavioral intention pada penerimaan aplikasi Brilian.

\section{Pengaruh Facilitating Conditions Terhadap Use Behavior}

Pada hasil analisis data bahwa diperoleh nilai t-statistics pada variabel facilitating conditions yaitu 2,358 lebih besar dari nilai t-tabe/ yaitu 1,64. Perolehan hasil original sample (O) yaitu positif 0,135 . Hasil tersebut menunjukkan adanya hubungan positif pada facilitating conditions terhadap behavioral intention, dengan demikian dapat disimpulkan bahwa facilitating conditions berpengaruh positif terhadap use behavior. Apabila facilitating conditions semakin meningkat maka behavioral intention akan semakin meningkat pada penerimaan dan penggunaan aplikasi OVO di Kota Denpasar.

Facilitating conditions yaitu menilai tingkat kepercayaan seseorang dalam menggunakan suatu sistem yang memiliki fasilitas, teknikal yang tersedia dan infrastruktur organisasional. Pada hasil penelitian ini menunjukkan bahwa fitur dan fasilitas pada aplikasi OVO memberikan kenyamanan dan keefektivan dalam penggunaannya, maka akan menunjukkan hubungan yang positif terhadap perilaku menggunakan. Hasil penelitian Egi Radiansyah (2017) yakni mendukung hasil penelitian ini, dimana disebutkan dalam penelitian Egi Radiansyah (2017) bahwa facilitating conditions berpengaruh signifikan terhadap use behavior pada penggunaan T-Cash. Dalam penelitiannya original sample $(\mathrm{O})$ dinyatakan positif.

\section{Pengaruh Experience Terhadap Facilitating Conditions Dengan Use Behavior}

Pada hasil analisis data bahwa diperoleh nilai t-statistics yaitu 1,077 lebih kecil dari nilai ttabel yaitu 1,64. Pada original sample (O) diperoleh hasil yaitu $-0,026$. Hal ini menunjukkan adanya hubungan negatif variabel experience terhadap facilitating conditions dengan use behavior. Berdasarkan pada hasil tersebut maka dapat disimpulkan experience tidak memperkuat hubungan facilitating condition dengan use behavior, ini berarti experience tidak mempengaruhi peningkatan maupun penurunan pada hubungan facilitating conditions dengan use behavior pada penerimaan dan penggunaan aplikasi OVO di Kota Denpasar.

Pada hasil penelitian tersebut jika seorang pengguna aplikasi OVO memiliki pengalaman yang buruk mengenai fitur dan fasilitas yang diberikan oleh OVO, maka tidak dapat meningkatkan pengaruh yang baik terhadap use behavior. Berdasarkan pada hasil penelitian tersebut, didukung dengan hasil penelitian oleh Khoirunnisak (2016). Pada hasil penelitiannya menyebutkan bahwa experience tidak dapat memperkuat hubungan facilitating conditions dengan use behavior pada penggunaan E-learning Share-ITS.

\section{Pengaruh Behavioral Intention Terhadap Use Behavior.}

Berdasarkan hasil yang diperoleh bahwa nilai t-statistics pada behavioral intention sebesar 8,100 lebih besar dari nilai t-tabel yaitu 1,64. Pada original sample $(0)$ diperoleh nilai yaitu positif 0,038 yang menunjukkan adanya hubungan positif variabel behavioral intention terhadap use behavior. Hasil analisis data tersebut dapat disimpulkan bahwa behavioral intention berpengaruh 
positif terhadap use behavior, hal ini berarti jika behavioral intention meningkat maka diikuti oleh use behavior yang akan meningkat pula pada penerimaan dan penggunaan aplikasi OVO di Kota Denpasar.

Pada penelitian ini behavioral intention merupakan penentu sejauh mana seseorang niat dalam menggunakan aplikasi OVO. Hasil dari penelitian ini menunjukkan bahwa behavioral intention berpengaruh positif terhadap use behavior, ini berarti bahwa pengguna aplikasi OVO memiliki keyakinan untuk menggunakan aplikasi OVO seterusnya. Dari hasil penelitian ini didukung dengan hasil penelitian oleh Putra (2019) yang mengemukakan bahwa use behavior berpengaruh positif terhadap use behavior pada penerimaan dan penggunaan Bitcoin.

\section{SIMPULAN DAN SARAN}

Pada hasil analisis data bahwa performance expectancy, effort expectancy dan social influence berpengaruh positif terhadap behavioral intention. Facilitating conditions dinyatakan berpengaruh positif terhadap use behavior, dan behavioral intention dinyatakan berpengaruh positif terhadap use behavior. Namun hasil tersebut berbanding terbalik pada variabel moderator, yaitu experience tidak memperkuat hubungan effort expectancy, social influence, facilitating conditions dengan behavioral intention dan use behavior. Voluntariness of use dinyatakan tidak memperkuat hubungan social influence dengan use behavior.

Berdasarkan pada hasil dari penelitian ini, diharapkan untuk penelitian selanjutnya menggunakan variabel moderasi sesuai dengan model UTAUT, baik model yang telah dimodifikasi atau sesuai dengan model UTAUT. Kedepannya diharapkan dapat menambah jumlah sampel, karena penggunaan e-money khususnya aplikasi OVO dapat meningkat kedepannya. Hasil penelitian ini digunakan sebagai sumber ajar atau studi kasus dalam kegiatan pada mata kuliah tertentu dan sebagai kajian pustaka dalam rangka melakukan penelitian. Bagi pengguna OVO diharapkan untuk meningkatkan konsistensi dalam menggunakan aplikasi OVO karena pengguna akan mendapatkan manfaat dalam kemudahan bertransaksi non tunai dan juga mendukung Gerakan Nasional Non Tunai (GNNT).

\section{REFERENSI}

Aningsih, F. (2015). "Pengujian Unified Theory Of Acceptance And Use Of Technology (UTAUT) Terhadap Perilaku Menggunakan E-Banking Mandiri (Studi pada Pengguna E-Banking Mandiri yang sedang Berada di Kec. Rajabasa Bandar Lampung)". UNIVERSITAS LAMPUNG.

Bank Indoneisa."Teknologi Finansial". Accesed August 1, 2019. Https:/Mww.Bi.Go.Id/ld/SistemPembayaran/Fintech/Contents/Default.Aspx

Bank Indonesia. "Uang Elektronik." Accesed August 1, 2019. Https:/Www.Bi.Go.Id/Id/EdukasiPerlindungan-Konsumen/Edukasi/Produk-Dan-Jasa-Sp/Uang-Elektronik/Pages/Default.Aspx

Bistolen, Adryana Suprihatin. 2018 “Analisis Persepsi Penerimaan Teknologi Pada Satuan”. 121. Jogiyanto. 2008. Sistem Informasi Keprilakuan. Yogyakarta: Andi Offset. 
Jogiyanto. 2015.Partial Least Square (Pls). Yogyakarta: Andi Offset

Ketut, Ni, Nita Rianadewi, Dewa Gede, Hendra Divayana, And Imade Ardwi Pradnyana. 2019. "Analisis Penerimaan Pengguna Sistem Informasi Perpustakaan Dan Arsip Daerah Kabupaten Buleleng Menggunakan Model Unified Theory Of Acceptance And Use Of Technology" Kumpulan Artikel Mahasiswa Pendidikan Teknik Informatika 8, no. 2: 394-403.

Khoirunnisak, Wahyu. 2016. "Implementasi Model Penerimaan Unified Theory Of Acceptance And User Of Technology (Utaut) Untuk Menganalisis Faktor-Faktor Penerimaan Dosen Terhadap Penggunaan E-Learning Share-Its."

Mentaya, Andre, M.J.Dewiyani Sunarto, And Sri Hariani Eko Wulandari. 2015. "Faktor-Faktor Yang Berpengaruh Terhadap Penerimaan Aplikasi Brilian Dengan Model Utaut." Jsika 4, no. 2: $1-10$.

Okta Rahmatanto, And Gadang Ramantoko. 2018. "Faktor Demografi Yang Mempengaruhi Minat Nasabah Pt. Bank Rakyat Indonesia Menggunakan Layanan Bri Mobile" e-Proceeding of Management 5, no.1: 398-405.

OVO. "Features". Accessed September 10, 2019. Https://Www.Ovo.Id/Features

OVO. "About US" Accessed September 10, 2019. https://www.ovo.id/about

Pertiwi, Ni Wayan Dewi Mas Yogi and Dodik Ariyanto. 2017 "Penerapan Model UTAUT2 Untuk Menjelaskan Minat dan Perilaku Penggunaan Mobile Banking Di Kota Denpasar." Journal of Chemical Information and Modeling 53, no. 9: 1689-99. https://doi.org/10.1017/CBO9781107415324.004.

Putra, I Gusti Agata Prisanta. 2019. "Is Bitcoin Accepted In Indonesia?" International Journal of Innovative Science and Research Technology 4, no.2: 424-30.

Radiansyah, Egi. 2017. "Analisis Pengaruh Penggunaan TCash Menggunakan Unified Theory Of Acceptance And Use Of Technology (UTAUT2) Studi Pada Mahasiswa Pengguna TCash Di Universitas Telkom." Journal of Chemical Information and Modeling 53, no. 9: 1689-99. https://doi.org/10.1017/CBO9781107415324.004.

Rahmatillah, Novirani and Rima Nuzla Fitri. 2018. "Analisis Pengaruh Perilaku Penggunaan Teknologi Fintech Pada Generasi Millenial Di Kota Bandung." Journal of Chemical Information and Modeling 53, no. 9: 1689-1699.

Sugiyono. 2017. Metode Penelitian Kuantitatif, Kualitatif, dan R\&D. Bandung: ALFABETA.

Yunis, Roni, Ayu Tiana, and Fitri Astuti. 2017. "Analisis Penerimaan Pengguna Akhir Dengan Model UTAUT: Peran Gender, Age, Dan Experience Dalam Menggunakan NOSS-F Systems," 189-94. 
Winduwiratsoko. 2018. "Analisis Penerapan Model Unified Theory Of Acceptance And Use Of Technology (Utaut) Untuk Memahami Penerimaan Dan Penggunaan Layanan E- Banking Oleh Nasabah Di Provinsi Daerah Istimewa Yogyakarta". 